\title{
A Study of the Impact of the Economic Downturn in Trinidad and Tobago (2015-2016) on Leadership Styles within the North Central Regional Health Authority
}

Aaron Baldeosingh* and Fidel Rampersad

Radiology Unit, The University of The West Indies, St. Augustine Campus, St Augustine, Trinidad and Tobago

\begin{abstract}
Background: The purpose of this study was to explore leadership styles within the NCRHA across top management levels, identifying common approaches to and/or styles of, leadership. The research sought to identify any perceived changes in approach that these reported as a consequence of the changed internal and external economic environments (economic environment in Trinidad in the period 2015-2016. In relation to the financial crisis, the heads of department in NCRHA had to change their leadership styles when managing staff, in order to continuously deliver quality's service to clients. To implement change successfully, there was a need for the organization's employees to adopt new behaviors in order to continuously deliver a high quality service. By carrying out an exploration of the leadership styles within the NCRHA, it was the intention to glean information from a series of interviews with managers responsible for delivering services across a range of disciplines. Although the researcher was initially unaware of what would be found, it was hoped that the information obtained would provide a richness of data which would enlighten the reader about the difficulties and subsequent approaches that needed to be adopted by leaders as they tried to deliver a service whilst operating in a difficult climate.
\end{abstract}

Study design/Methodology: The research favored a mixed method approach, using quantitative and qualitative methods to gather data; a descriptive, cross-sectional, quantitative survey design was utilized. Data were collected from a convenience sample of medical, allied and non-allied staff at the NCRHA. Eligibility criteria included:

- Employment at the NCRHA on or before October 2015 and assignment to the hospital;

- Trinidad and Tobago resident status;

- Age between 25 yrs and 55 yrs.

The sample size was limited to five departments in the NCRHA: clinical (Medicine, Surgery, Radiology,) and nonclinical (Quality, Social Services, and Customer Service) Departments. The sample consisted of 100 participants from these departments. Structured questions were used in researcher-administered surveys.

For the conduct of structured interviews, participants were contacted two weeks prior to proposed date and sent the initial questions. The format of the interview was explained to each interviewee and any questions were answered prior to the start. There were no distractions or interruptions during any of the six interviews, which took place outside of the participants' offices and helped with the process. All interviews were recorded by being transcribed. In this instance, the sample size was six participants with a gender mix of three males and three females who functioned within a blend of clinical and administrative roles, had different levels of responsibility and managed different service.

Major findings: The research findings were positively correlated to the research's aims and objectives. It was noted that, among the middle managers in the system, leadership styles had changed to a significant extent as a result of the economic downturn. There were both strengths and weaknesses in leadership behavior highlighted as a result of the research.

Recommendations: In order to maintain the changes, it is necessary to evaluate and take a 360-degree review of all systems, whether attendance policies or financial regulations. This will involve the managers reviewing their own positions, and identifying the strengths and weaknesses of each system. Failure to acknowledge the findings will only serve to undermine the organization's ability to move forward, further damaging its reputation and stifling the opportunity to meet its potential as a world-class health service.

Keywords: Hospital, human; Economic, Surgery; Radiology; Medicine; Financial crisis

\section{Introduction}

In relation to the financial crisis, the heads of department in NCRHA had to change their leadership styles when managing staff, in order to continuously deliver quality`s service to clients. To implement change successfully, there was a need for the organization's employees to adopt new behaviors in order to continuously deliver a high quality service. The importance of conducting this study from an action-based perspective was to determine the extent to which the organization's leaders voluntarily changed their leadership and management styles as a consequence of new austerity measures in force. The results are
*Corresponding author: Aaron Baldeosingh, Radiology Unit, The University of The West Indies, St. Augustine Campus, St Augustine, Trinidad and Tobago, Tel: +18684752161; E-mail: aaronbaldeosingh@gmail.com

Received September 11, 2017; Accepted October 10, 2017; Published Octobe 17,2017

Citation: Baldeosingh A, Rampersad F (2017) A Study of the Impact of the Economic Downturn in Trinidad and Tobago (2015-2016) on Leadership Styles within the North Central Regional Health Authority. Health Econ Outcome Res Open Access S1: 101. doi: 10.4172/2471-268x.1000. S1-101

Copyright: ( 2017 Baldeosingh A, et al. This is an open-access article distributed under the terms of the Creative Commons Attribution License, which permits unrestricted use, distribution, and reproduction in any medium, provided the original author and source are credited. 
intended to help the leaders to maintain efficient operations in the face of reduced finances, as well as to highlight the benefits of more flexible management styles.

In relation to the NCRHA before the financial recession of 20152016 the leadership styles that most department exhibited where a transformation leadership style. This type of leadership is required for a hospital setting to manage radical change which is always occurring in a hospital setting. In the face of environmental uncertainty, they visualize what the organization must able to, rally the organization to accept and labor toward achieving the new vision and institutionalize the changes to last. When stable times existed in the NCRHA the leaders simply finetuned exhibiting policies with the integration process. However, the change from a transformational to transaction leadership style causes a chaotic environment to occur and the leaders are required to take a structure breaking transformation. The recognition comes through scanning the opportunities, threats, construction, and implementation of a new image before an external calamity causes change.

The NCRHA had to develop a complex adaptive system in which leaders were under extreme pressure to deliver high quality services with limited resources. In addition to coping with reductions in funding of seven percent over the last year, the NCRHA also dealt with a workforce that had taken several budget cuts in resources in relation to human resources and equipment, and was exhibiting symptoms of low morale. Because of the limited supply of human resources and equipment, workers in this health sector institution experienced difficulties in providing the required high quality of service to clients. It is for this aim that leadership within the NCRHA seemed commendable of research.

An autocratic leadership style has previously existed in the health system; though, through the local framework, this study aimed to report the implications of leadership style as a direct importance of the effects of the economic downturn in Trinidad and Tobago, which established as a result of the Global Financial Crisis (GFC). This thesis attempted the following:

i. To establish whether professed leadership styles had altered as a result of the external environment (the economy) manipulating the internal environment, and the impact of the changed leadership behaviors on employee action and the resulting service delivery.

ii. To carry out an examination of the leadership styles inside the NCRHA so as to provide information that would highlight, for the reader, the problems encountered and the approaches now being implemented by leaders and managers as they operate in a difficult climate.

iii. To institute where, if any, recommendations could be made for improvement with regard to the leadership procedures within the NCRHA.

\section{Literature Review}

This section begins by briefly addressing the effects of the global financial crisis (GFC). Fox et al. [1] states that, in the early 1930s, procedure errors by governments and central banks spun a financial crisis into a global economic disaster. In 2008, the financial shockwave was at least as big, but the feedback was smarter and the result less severe. Lessons had essentially been learnt in the prevailing threequarters of a century around how the economy and the financial system fit together [1]. The literature review puts this study in context by examining the effects of the GFC. It also exhibits how this study narrates to the work of other researchers in this playing field, and covers nearly all of the key current leadership theories, as well as the consequences of leadership behavior on staff morale and the achievement of the organization's mandate. The assertions made in this thesis are grounded on qualitative and quantitative information as a result of the investigator's interviewing several colleagues who are important stakeholders across a diversity of disciplines in healthcare, and surveying staff under top managers.

As governance is such an expansive topic, the following paragraphs will study types of leadership style, especially in the public area, taking cognizance of the financial conditions which Trinidad endured since the start of the global financial crisis in 2015 .

During this current economic downturn some employees are experiencing a new type of leader emerging within their organizations. It seems no longer viable to just have managers within organizations, they are looking for great leaders to influence and affect their surroundings for the benefits of the organization and the employees. Bennis [2] suggests "Managers do things right" but leaders "do the right things". However, Mintzberg et al. [3] argues that leadership traits are part of the managers' overall role. Mintzberg et al. [3] identified 3 areas; interpersonal, informational and decisional which would seem appropriate for any manager or great leader to possess.

\section{Methods}

This chapter delivers descriptions of the research project, the population plus the sample, the setting, the instruments used to collect reliable and valid data, and the statistical analysis performed.

The research utilized a mixed-method project that analyzed quantitative and qualitative information. Data were collected from a convenience sample of medical, allied and non-allied staff at the NCRHA who was asked to respond to structured, researcheradministered questions. Eligibility criteria included: employment at the NCRHA on or before October 2015 and assignment to the hospital Trinidad and Tobago resident status; and age between $25 \mathrm{yrs}$ and $55 \mathrm{yrs}$. The sample size was limited to 100 participants from five departments in the NCRHA: clinical (Medicine, Surgery, Radiology) and nonclinical (Quality, Social Services, and Customer Service) Departments.

The interviewees who provided qualitative data were called two weeks in advance of proposed period, and sent the primary questions. The layout was clarified to each partaker plus any questions were responded to preceeding to the start of the meeting. The atmosphere was relaxed and there were no interruptions or interruptions during the interviews which took place external of the participant's offices. All interviews were recorded by being transcribed. The sample size was six participants with a gender mix of three males and three females. Participants were selected from a mix of clinical and administrative employees. Each participant was asked the same open-ended questions listed as Appendix B.

Numerous sources of information were compulsory to acquire the solutions to the research problem. Six Heads of Department were interviewed using the interview questions in Appendix B. The questions were then studied for suitability then to guarantee they permitted open communication amongst the interviewer in addition to interviewee. To ensure that workers may perhaps contribute a reasonable image of whatever they believed the leaders of these establishments had to offer their teams and whether or not their styles transformed at the beginning of the recession, both quantitative and qualitative research 
Citation: Baldeosingh A, Rampersad F (2017) A Study of the Impact of the Economic Downturn in Trinidad and Tobago (2015-2016) on Leadership Styles within the North Central Regional Health Authority. Health Econ Outcome Res Open Access S1: 101. doi: 10.4172/2471-268x.1000. S1-101

Page 3 of 9

methods where used. Using an inductive, qualitative approach, the information was gathered and data available were formulated on the research theme. The use of an empirical, quantitative method permitted the evidence received from questionnaires plus structured interviews to support with the investigation.

These questionnaires echoed what workers believed to stand by the leadership styles of their managing teams, requesting them to hand-pick the suitable style both in advance and later and say how this affected the principles of their departments since the beginning of the recession. This qualitative study was concerned through understanding and individual experiences. These questionnaires were given to a range of employees in medical and non-medical departments within the institutions. Initially questionnaires were issued by hand to establish findings for the research.

The data collecting was aimed to focus on and also record those observations on the particular research issue. Primary data sources were used to review the affected leadership style forced on the economically-driven change which resulted from the recession. The investigation from the principal data described the understanding of employees in the sample. Interviewing is one of the utmost shared methods for any small-scale research. Semi-structured interviews possibly will also be flexible, dependent on the responses established throughout the interviews. The information was noted in notes and recorded.

Authorization was required and attained from the Ethics Committee and the Department of Public Health Observatory prior to the conduct of the survey (Appendix A). Following the approvals, packets were distributed to the 100 participants from the five departments who met the eligibility criteria outlined previously. The six Heads that were to be interviewed were notified two weeks in advance via telephone. The packets and the interview questions were distributed personally by the researcher. The packets included a questionnaire and a cover letter (Appendix A), while the interview questions included a cover letter which described the practicum and its purpose, and a list of questions. The e-mail address of the researcher also with the cell phone number was also included, giving the participants a means to contact the investigator with any questions or queries. The questionnaire was placed in a stamped, self-addressed envelope.

Participants were given the option of completing the questionnaire on the same day and returning it to the researcher who collected them in person, or alternatively posting their responses in the stamped self-addressed envelope within five days. Informed approval was inferred by completion in addition to returning of the questionnaires. Confidentiality of the members was maintained by using only number codes on the respondents' surveys and destroying the information after the results were analyzed. No names of respondents were included in the questionnaire. The closing of the envelopes containing the finished surveys certified that only the researcher viewed the actual surveys. The Department of Public Health Observatory had no access to the completed surveys. The interviews were conducted in the participants' private offices, at a time convenient to them. Each interview took approximately $30 \mathrm{~min}$ to $45 \mathrm{~min}$ and responses, once transcribed, were destroyed to maintain confidentiality. Informed consent was implied by accepting to take part in the interview process. On the transcription, no names of applicants were recorded. The Department of Public Health Observatory will not have access to the completed interviews done by the heads of departments; they may request and attain access to the final thesis

\section{Results}

\section{Theme 1: Leadership style}

From the findings, the majority of leaders exhibited a transformational leadership style before the recession. In the analysis of the data it was found in the study population of the five candidates who were interviewed, $40 \%$ described themselves as transformational, $20 \%$ task-oriented and 20\% each, bureaucratic and democratic.

\section{Theme 2: Staff perception of your leadership style}

From further discussion in the interview process it was found that the majority of the leaders $(80 \%)$ thought that their staff perceived them to be task-oriented and $20 \%$ bureaucratic. It is a substance of reliant corroboration of employees grounded on performances. It inspires juniors by alluring to their individual requirements, founded on influential financial relations.

Through reference to the developing conditions which mature through group interface, the results exposed that relationship-oriented leaders produced superior cohesion amongst members of the group; however a more task-oriented style of leadership did not produce alterations in the developing states. The outcome of leadership style on group procedures stood different: task-oriented leaders prompted greater group efficacy, a more positive and less negative disturbing state among followers of the group, while additional relationshiporiented leaders did not bring noteworthy changes in relation to group procedures. These consequences are dependable in terms of the consequence of leadership style proceeding performance. Individuals, who observed their leaders as more task-oriented, attained higher levels

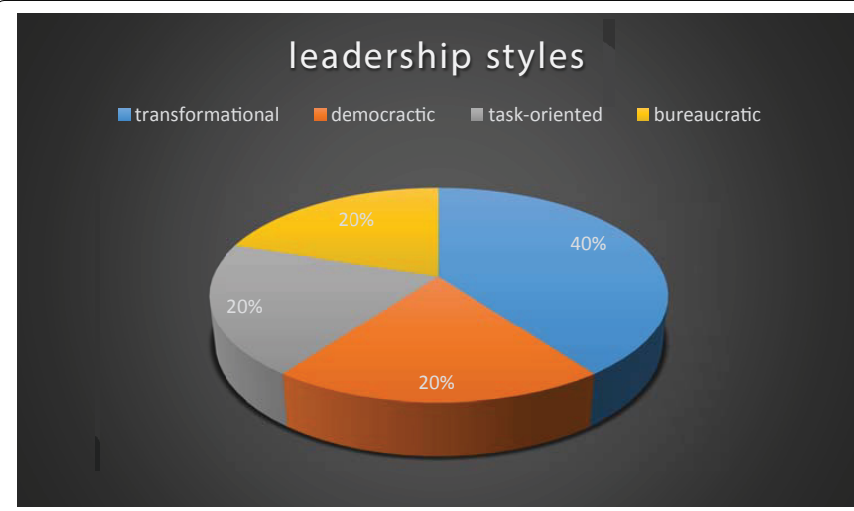

Theme 1: Leadership style.

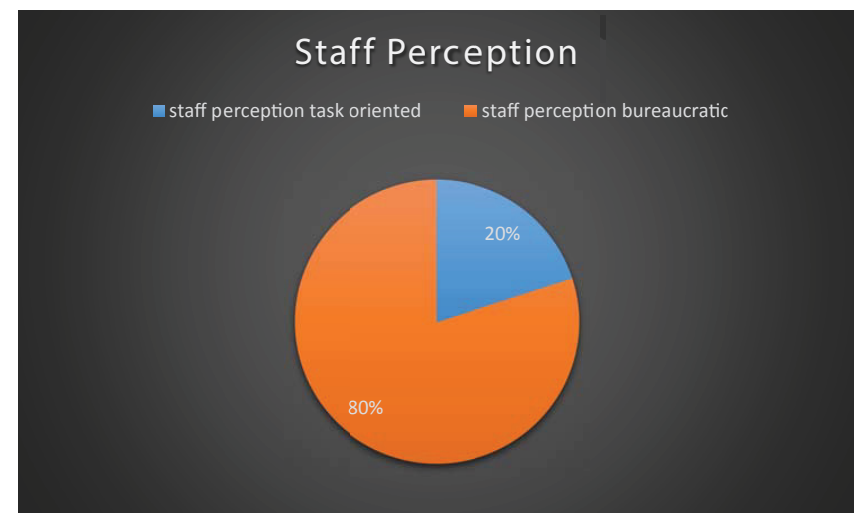

Theme 2: Staff perception of your leadership style. 
Citation: Baldeosingh A, Rampersad F (2017) A Study of the Impact of the Economic Downturn in Trinidad and Tobago (2015-2016) on Leadership Styles within the North Central Regional Health Authority. Health Econ Outcome Res Open Access S1: 101. doi: 10.4172/2471-268x.1000. S1-101

of task achievement. Not at all changes were established in performance when leaders demonstrated a more relationship-oriented style of leadership. The outcomes of this study usually deliver backing to the discoveries of further studies, which have revealed the noteworthy role played by the leader in the expansion of group developments.

\section{Theme 3: The impact of the recession on the team}

Forty percent of the team had increased staff participation, $40 \%$ where demotivated and $20 \%$ had a positive change; from the data it can be shown that the staffs were equally divided in their decision making.

\section{Theme 4: The consequences of change in leadership style}

The variations exhibited by the change in leadership show a $40 \%$ change, $40 \%$ no change and $20 \%$ positive change. Researchers have recognized the significant role that organizational leadership shows in empowering employees. Conferring to Spreitzer [4], two work context factors govern employees 'feeling of enablement: info and rewards. Precisely, evidence about the organization's mission also with information near performance are critical for permitting employees. Without being up-to-date about where the organization is directed, workers will not be capable to have the sense of control or else being involved; without performance information, workers will not be able to know how well their performance are, which is essential to supporting a sense of competency [4].

\section{Theme 5: Changes in the organization that affect the delivery of service to clients}

The change on leadership of the managers and organization had

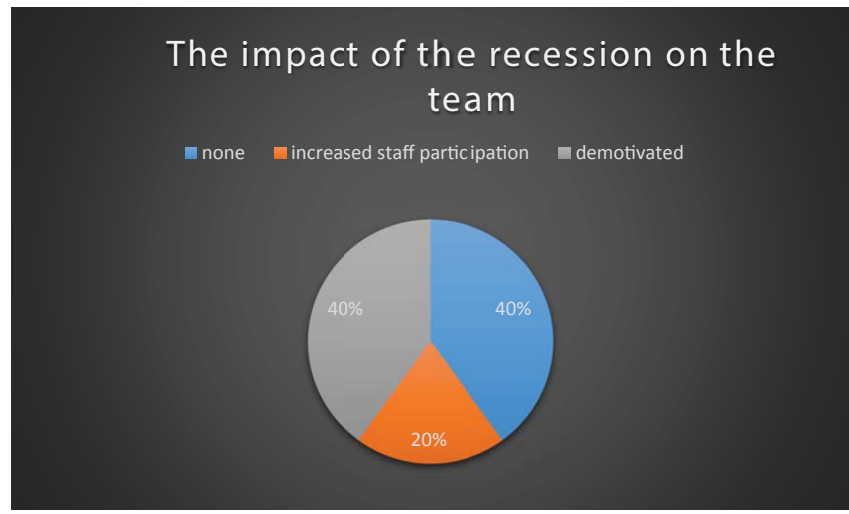

Theme 3: The impact of the recession on the team.

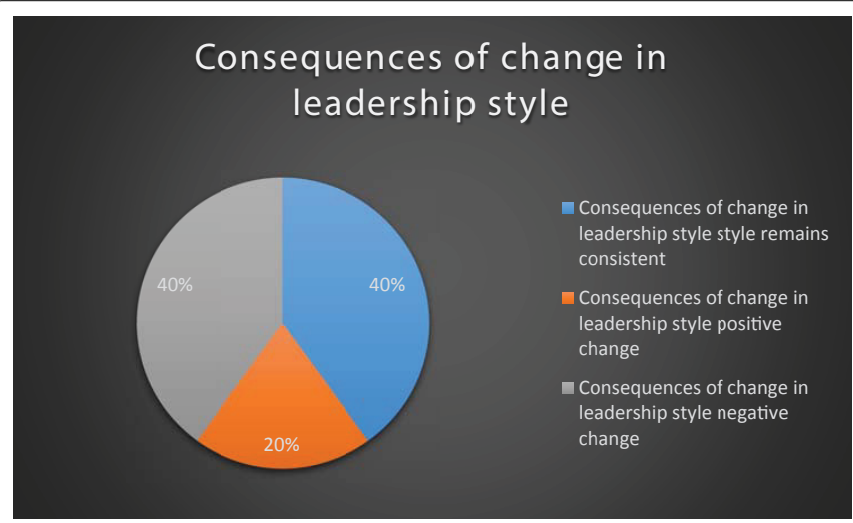

Theme 4: The consequences of change in leadership style.
$60 \%$ no change and a $40 \%$ improvement in the delivery of services to the organization. This represented a negative view of the organization that the service was not improving.

\section{Theme 6: Changes in the organization that have affected the quality of service}

Owing to the change in leadership style the quality of service was impacted there was an increase in waiting times as indicated by the $40 \%$ of the staff indicated this, $20 \%$ each for quality of service, culture change and greater accountability.

\section{Quantitative}

\section{Background information}

Proceeding the contextual of the respondents, a number of variables were examined. The attention here was to measure the level of attachment of the respondents to their institute. The consequences on the background data of the respondents are shown in the subsequent presentation.

\section{Age distribution of respondents}

By way of observation from Table 1 above, it is clear that the bulk of respondents, $41(41 \%)$ were in the age range of $36-45$, this was proceeded by 39 (39\%) in the age range of $25-35$, though the least age range was $46-55$ which was represented by solitary $20(20 \%)$. This meant that the main respondents (who took part in the study) were ages $36-45$

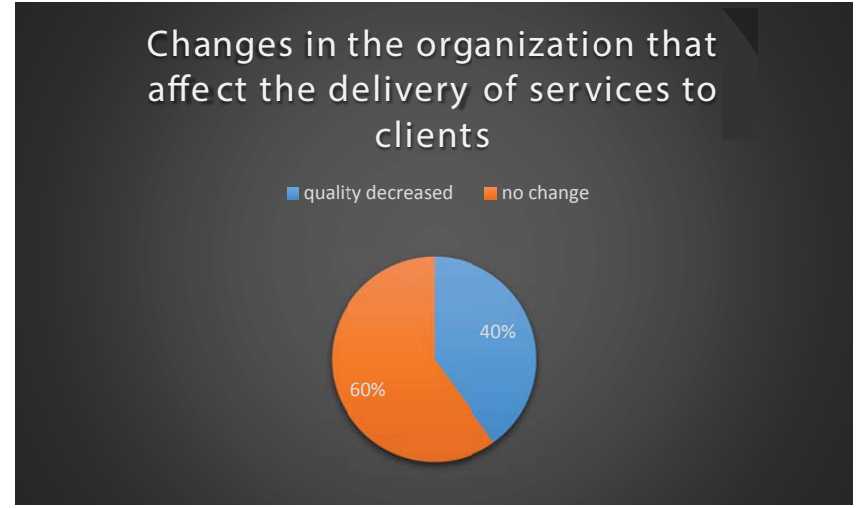

Theme 5: Changes in the organization that affect the delivery of service to clients.

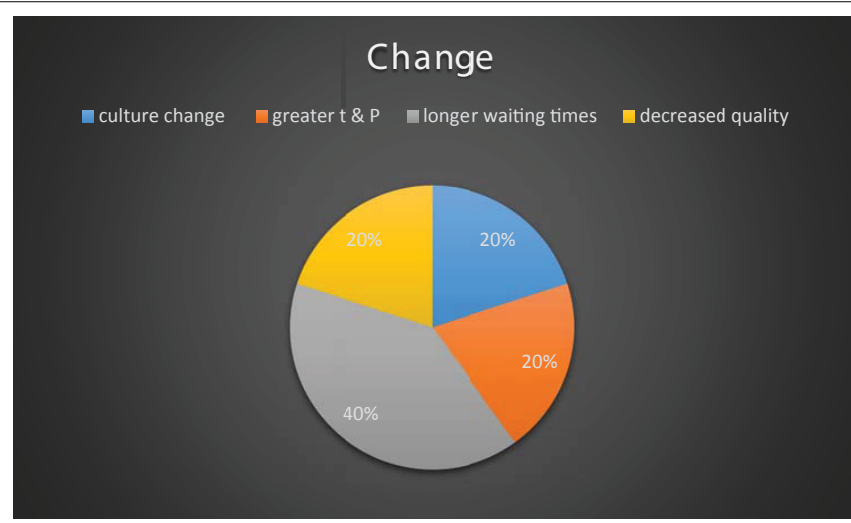

Theme 6: Changes in the organization that have affected the quality of service. 
Citation: Baldeosingh A, Rampersad F (2017) A Study of the Impact of the Economic Downturn in Trinidad and Tobago (2015-2016) on Leadership Styles within the North Central Regional Health Authority. Health Econ Outcome Res Open Access S1: 101. doi: 10.4172/2471-268x.1000. S1-101

Page 5 of 9

\section{Distribution of respondents by Sex}

The concentration here was to form a connection of the sex of a respondent with the leadership style of the RHA. As detected from Tables 2 and 3, it is clear that the popular of the respondents, $60(60 \%)$ were female as contrasting to males who were $40(40 \%)$. This presumes that usually, the margin among males in addition to females is marginal. This inferred that there was equivalent illustration of the male and female workers in the North Central Regional Health Authority.

\section{Distribution of respondents by years of service}

This dissemination was proposed to answer the query of experience and how it connected to the performance of their leaders in the North Central Regional Health Authority. As seen in the table above, most of the twenty-eight respondents had 3-5 yrs' experience in NCRHA, $12(12 \%)$ had in 11-15 yrs' experience and 20 (20) were in the category of 16-20 yrs of service at the NCRHA. The highest representation was $36 \%$ in the 6-10-yr category, which inferred that most workers' in NCRHA had adequate experience at their work stations to benefit, perform duties acceptably. In examining employee performance and leadership styles, the question of less experience may not relate.

\section{Substantiation of Research Objective One (1)}

The earliest objective of the study began from the research question which asked whether observed leadership styles had transformed as a consequence of the outside environment's manipulating the internal environment (NCRHA). To authenticate this objective, the data were examined by use of S.P.S.S and the subsequent products were presented as perceived below:

Bestowing to Table 4, the uppermost response rate was noted on the last item, with a occurrence of 40 . Respondents believed that their leaders were task-oriented and only concerned with getting the job done at whatever cost. This was noticed through a rigid environment in the past where policies where implemented without communication with the employees.

\begin{tabular}{|c|c|c|c|}
\hline & Frequency & Percent & Cumulative percent \\
\hline $25-35$ & 39 & 39 & 39 \\
\hline $36-45$ & 41 & 41 & 80 \\
\hline $46-55$ & 20 & 20 & 100 \\
\hline Total & 100 & 100 & \multicolumn{2}{|c|}{ Table1: Age in years. } \\
\hline \multicolumn{2}{|c|}{} \\
\hline
\end{tabular}

\begin{tabular}{|c|c|c|c|c|}
\hline & & Frequency & Percent & Cumulative percent \\
\hline \multirow{3}{*}{ Valid } & Male & 40 & 40 & 40 \\
\cline { 2 - 5 } & Female & 60 & 60 & 100 \\
\cline { 2 - 5 } & Total & 100 & 100 & \\
\hline
\end{tabular}

Table 2: Sex.

\begin{tabular}{|c|c|c|c|}
\hline & Frequency & Percent & Cumulative percent \\
\hline 03-May & 28 & 28 & 28 \\
\hline 06-Oct & 36 & 36 & 64 \\
\hline Nov-15 & 12 & 12 & 76 \\
\hline $16-20$ & 20 & 20 & 96 \\
\hline $21-25$ & 4 & 4 & 100 \\
\hline Total & 100 & 100 & \\
\hline
\end{tabular}

Table 3: Number of years' service.
Conferring to Table 5, the maximum response rate was prominent on the second of last entry, by a frequency of 39 . Respondents believed they were not adequately communicated with and they were in disagreement as to the communication between them and their leaders. It is in contradiction of human nature to react positively to variation since it takes individuals out of their comfort zone. From the data it can be understood individuals react to changes in their work. The characteristic reaction is confrontation. Such resistance can frequently sabotage the best labors of management to be initiative of change throughout the organization. It even occurs when managers are hardworking communicators and active in the communication procedure.

When change initiatives flop, the culprit is frequently a absence of good communication from management. But that's not always the complete story. Communication isn't just near what management speaks - it's also about how staffs listen. In crafty the communication phase, you are starting to prepare your association for the change from present state, or practice, to the upcoming state. By this time, leaders need to concoct the messages that describe the organization's written principles and standards. In undertaking so, leaders will start to set the stage for behavioral and performance prospects.

The highest rate of responses was noted in "less supplies due to finances" which had a frequency of 59 from the table above, according to Table 6 . Limited supplies as indicated by the participants it can be demonstrated that from Table 6

According to Table 7, there were 88 frequencies which indicated a negative change due to the recession. The negative factors that where indicated in Table 6 from before are reduction in overtime (frequency 2), fewer supplies due to finances (frequency 59), reduction of staff which had a frequency of 24 and reduced quality of work which had a frequency of 2 .

According to Table 8, there was a 48 frequency in the task-oriented response by the participants after the recession. This indicated a change from before Table 4 from a frequency of 40 to 48 demonstrating that the leaders were becoming more demanding of their staff to get the job done. The short-comings as indicated in Table 6 due to the recession indicated this.

\begin{tabular}{|c|c|c|c|c|c|}
\hline \multicolumn{2}{|c|}{} & Frequency & Percent & Valid Percent & $\begin{array}{c}\text { Cumulative } \\
\text { percent }\end{array}$ \\
\hline \multirow{4}{*}{ Valid } & autocratic & 32 & 32.0 & 32.0 & 32.0 \\
\cline { 2 - 6 } & democratic & 8 & 8.0 & 8.0 & 40.0 \\
\cline { 2 - 6 } & bureaucratic & 12 & 12.0 & 12.0 & 52.0 \\
\cline { 2 - 6 } & laissez-faire & 8 & 8.0 & 8.0 & 60.0 \\
\hline & task oriented & 40 & 40.0 & 40.0 & 100.0 \\
\hline & Total & 100 & 100.0 & 100.0 & \\
\hline
\end{tabular}

Table 4: Leadership style of manager before the recession.

\begin{tabular}{|c|c|c|c|c|c|}
\hline \multicolumn{2}{|c|}{} & Frequency & Percent & Valid percent & $\begin{array}{c}\text { Cumulative } \\
\text { percent }\end{array}$ \\
\hline \multirow{4}{*}{$\begin{array}{c}\text { strongly } \\
\text { agree }\end{array}$} & 7 & 7.0 & 7.0 & 7.0 \\
\cline { 2 - 6 } & agree & 3 & 3.0 & 3.0 & 10.0 \\
\cline { 2 - 6 } & nalid & 14 & 14.0 & 14.0 & 24.0 \\
\cline { 2 - 6 } & disagree & 39 & 39.0 & 39.0 & 63.0 \\
\cline { 2 - 6 } & $\begin{array}{c}\text { strongly } \\
\text { disagree }\end{array}$ & 37 & 37.0 & 37.0 & 100.0 \\
\hline & Total & 100 & 100.0 & 100.0 & \\
\hline \multicolumn{4}{|c}{ Table 5: Communication. } \\
\hline
\end{tabular}




\begin{tabular}{|c|c|c|c|c|c|}
\hline & Frequency & Percent & $\begin{array}{c}\text { Valid } \\
\text { percent }\end{array}$ & $\begin{array}{c}\text { Cumulative } \\
\text { percent }\end{array}$ \\
\hline \multirow{6}{*}{ Valid } & no effective change & 13 & 13.0 & 13.0 & 13.0 \\
\hline & reduction in overtime & 2 & 2.0 & 2.0 & 15.0 \\
\hline & $\begin{array}{l}\text { less supplies due to } \\
\text { reduce finances }\end{array}$ & 59 & 59.0 & 59.0 & 74.0 \\
\hline & reduction of staff & 24 & 24.0 & 24.0 & 98.0 \\
\hline & $\begin{array}{l}\text { reduced quality of } \\
\text { work }\end{array}$ & 2 & 2.0 & 2.0 & 100.0 \\
\hline & Total & 100 & 100.0 & 100.0 & \\
\hline
\end{tabular}

Table 6: Impact of events at the start of the recession.

\begin{tabular}{|c|c|c|c|c|c|}
\hline \multicolumn{2}{|c|}{} & Frequency & Percent & Valid percent & Cumulative percent \\
\hline \multirow{2}{*}{ Valid } & positive & 12 & 12.0 & 12.0 & 12.0 \\
\cline { 2 - 6 } & negative & 88 & 88.0 & 88.0 & 100.0 \\
\cline { 2 - 6 } & Total & 100 & 100.0 & 100.0 & \\
\hline
\end{tabular}

Table 7: Change at the beginning of the recession.

\begin{tabular}{|c|c|c|c|c|c|}
\hline \multicolumn{2}{|c|}{} & Frequency & Percent & Valid percent & $\begin{array}{c}\text { Cumulative } \\
\text { percent }\end{array}$ \\
\hline \multirow{4}{*}{ Valid } & autocratic & 28 & 28.0 & 28.0 & 28.0 \\
\cline { 2 - 6 } & democratic & 8 & 8.0 & 8.0 & 36.0 \\
\cline { 2 - 6 } & bureaucratic & 12 & 12.0 & 12.0 & 48.0 \\
\cline { 2 - 6 } & laissez-faire & 4 & 4.0 & 4.0 & 52.0 \\
\cline { 2 - 6 } & task oriented & 48 & 48.0 & 48.0 & 100.0 \\
\hline & Total & 100 & 100.0 & 100.0 & \\
\hline
\end{tabular}

Table 8: Leadership style of managers after the recession.

\section{Leadership of manager before recession}

Leadership of manager before recession Figure 1,

\section{Leadership style of manager after recession}

On further analysis of the change in leadership styles of before and after the recession a comparative analysis was conducted. From Figures 1 and 2 they demonstrated a slight change in leadership style. Figure 1 showed a mean of 2.16 and a standard deviation of 1.745 , Figure 2 showed a mean of 2.36 and a standard deviation of 1.75 . The changes in the mean value from comparing both showed that there was a small change but not of significant, this can also be seen in the standard deviation Figure 2.

Table 9 indicates that when the recession occurred, the change before was associated with adjustment after. The significance worth produced was 0.000 . The significance worth of 0.000 was less than 0.05 ; consequently, the research objective is accepted: that leadership had changed as a result of the recession. The change in the overhead data infers that the features of are significant for workers ' performance. This data also suggests that workers believe that they want to experience characteristics of better-quality of responsibility, better employee relations, increased consultation and discussion between them in addition to their supervisors, contribution in appraisals and consultations in decision creating.

From the statistics analyzed in the research, it was shown that there was a change in leadership style in some aspects. The leadership style previously was a task-oriented style but this style of leadership increased from a frequency of 32 to 40 from Tables 4 and 6. Although statistically the difference was a change of frequency of 8 , it can be noted as important to this setting.

What is the relationship between leadership and the adaptation of the team to this new leadership? Subsequent to this research

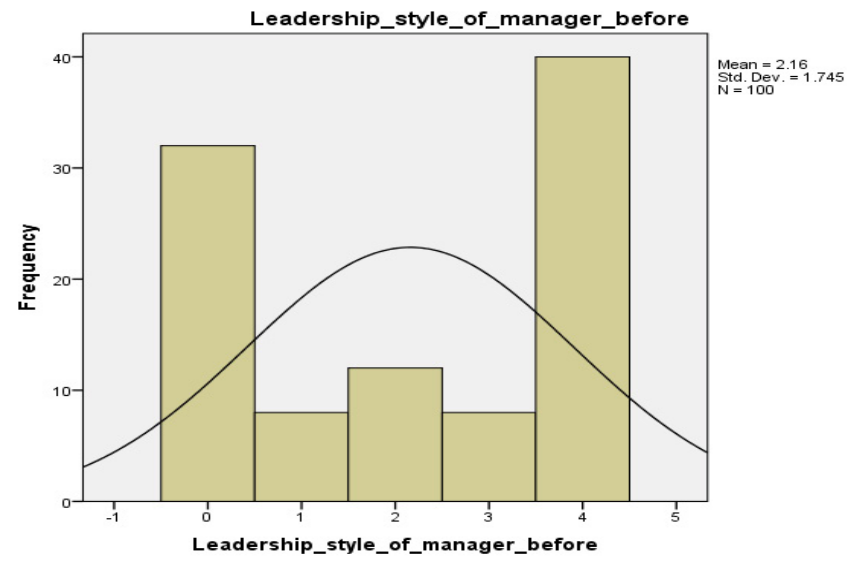

Figure 1: Leadership of manager before recession.

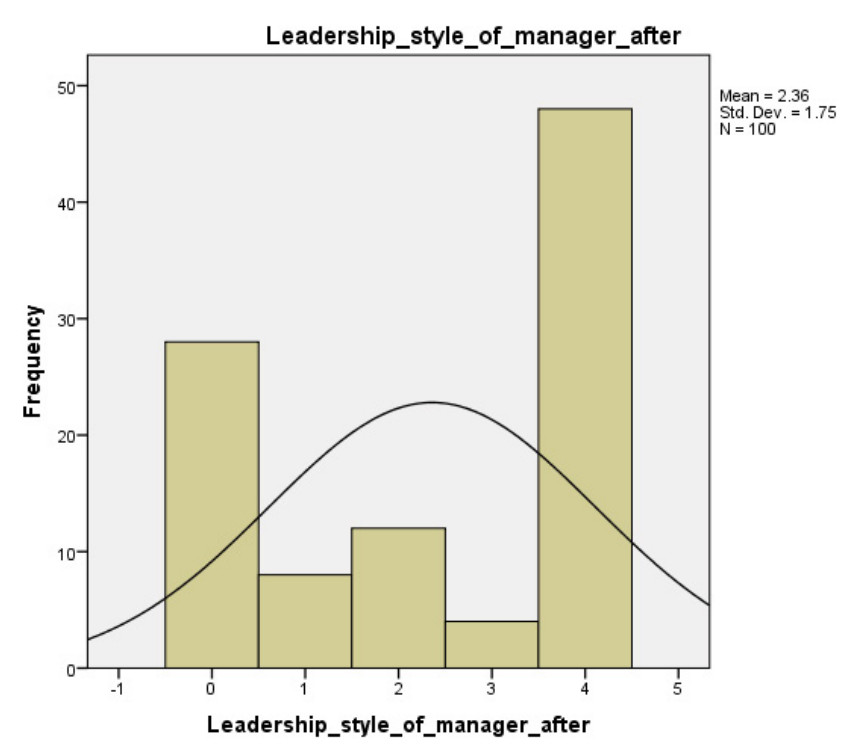

Figure 2: Leadership style of manager after recession.

\begin{tabular}{|c|c|c|c|}
\hline \multicolumn{2}{|c|}{ Correlations } & $\begin{array}{l}\text { Leadership style of } \\
\text { manager before }\end{array}$ & $\begin{array}{l}\text { Leadership style of } \\
\text { manager after }\end{array}$ \\
\hline \multirow{3}{*}{$\begin{array}{l}\text { Leadership style of } \\
\text { manager before }\end{array}$} & $\begin{array}{l}\text { Pearson } \\
\text { Correlation }\end{array}$ & 1 & $.682^{* *}$ \\
\hline & \multicolumn{2}{|c|}{ Sig. (2-tailed) } & 0 \\
\hline & $\mathrm{N}$ & 100 & 100 \\
\hline \multirow{3}{*}{$\begin{array}{l}\text { Leadership style of } \\
\text { manager after }\end{array}$} & $\begin{array}{l}\text { Pearson } \\
\text { Correlation }\end{array}$ & $.682^{* *}$ & 1 \\
\hline & Sig. (2-tailed) & 0 & \\
\hline & $\mathrm{N}$ & 100 & 100 \\
\hline
\end{tabular}

Table 9: Correlation of the changes of management style before and after the recession.

question, the answer to the objective was that: there was an undesirable relationship between leadership style and adaptation. This answer to the objective is however to be confirmed and the subsequent are respondent frequencies plus means generated from the respondents responses in the questionnaire.

Rendering to the product means produced from the above table, employees assumed that the leadership style adapted by their 
supervisors was not properly assessed which was proved by the means 1.09 , since only 36 agreed to this statement. The declaration that leadership rules are designed by supervisors was apparent enough for the researcher subsequently all 81 employees assumed so by negative and positive responses.

The products of Pearson's correlation amongst management styleadapted leadership in addition to the leadership style after the recession is a product of 0.024 which is less than 0.05 . This infers that there is a positive relationship amongst these two variables. Although such results are offered, it is thought that on this objective, most information presented the inference that workers were pressured to perform for the organization. Throughout the interview sessions, most staff believed that authoritative leadership conveyed roughly performance in an autocratic way and that additional forms of leadership performance would approach the employee in a more humanistic way.

\section{Substantiation of Research Objective Two (2)}

The second objective which is to carry out an exploration of the leadership styles within the NCRHA. The answers in Table 10-12 exemplified the fact that most employees (36\%) disagreed that there was leadership autonomy in their sections. This inferred that, in utmost departments, there was a smaller amount of freedom for the application of flexible leadership. Utmost departments that experienced the taskoriented leadership style had an enormous occurrence of undesirable feelings towards the organization to the range that no one was concerned about what the actual rules of performance where, further than the ability to gratify the supervisor's desires. In using the Pearson's correlation, a product highlighted culture plus produced a product of 0.002 which is fewer than 0.05 . This implied that, the manager was swayed by social behaviors. The claim was that culture had a positive

\begin{tabular}{|c|c|c|c|c|c|}
\hline \multicolumn{2}{|c|}{} & Frequency & Percent & $\begin{array}{c}\text { Valid } \\
\text { percent }\end{array}$ & $\begin{array}{c}\text { Cumulative } \\
\text { percent }\end{array}$ \\
\hline \multirow{3}{*}{ Valid } & have adapted well & 36 & 36.0 & 36.0 & 36.0 \\
\cline { 2 - 6 } & no change & 19 & 19.0 & 19.0 & 55.0 \\
\cline { 2 - 6 } & $\begin{array}{c}\text { negative attitude to } \\
\text { change }\end{array}$ & 45 & 45.0 & 45.0 & 100.0 \\
\cline { 2 - 6 } & Total & 100 & 100.0 & 100.0 & \\
\hline
\end{tabular}

Table 10: Leadership team adapted.

\begin{tabular}{|c|c|c|c|}
\hline & & $\begin{array}{l}\text { Leadership team } \\
\text { adapted }\end{array}$ & $\begin{array}{l}\text { Leadership style of } \\
\text { manager after }\end{array}$ \\
\hline \multirow{3}{*}{$\begin{array}{l}\text { Leadership } \\
\text { team adapted }\end{array}$} & $\begin{array}{l}\text { Pearson } \\
\text { Correlation }\end{array}$ & 1 & .024 \\
\hline & Sig. (2-tailed) & & .812 \\
\hline & $\mathrm{N}$ & 100 & 100 \\
\hline \multirow{3}{*}{$\begin{array}{l}\text { Leadership } \\
\text { style of } \\
\text { manager after }\end{array}$} & $\begin{array}{l}\text { Pearson } \\
\text { Correlation }\end{array}$ & .024 & 1 \\
\hline & Sig. (2-tailed) & .812 & \\
\hline & $\mathrm{N}$ & 100 & 100 \\
\hline
\end{tabular}

Table 11: Pearson`s correlation between management style adapted and change in leadership style after the recession. relationship through the manager's leadership style. Even though results were presented, it is understood that on this objective, most information accessible that the implication that employees were coerced to achieve for the organization.

\section{Substantiation of Research Objective Three (3)}

The third objective which stated: "to establish wherever, if at all any, recommendations could be prepared for enhancement with regard to the leadership processes within the NCRHA". The main reason of this was to asses empirically the influence of leadership style on organizational performance. The two measures of organization performance, which was the standard variable in this study, were effectiveness and efficiency; similarly, leadership style, which remained the predictor variable, remained operationalized into three empirically, depictions: autocratic, task-oriented, laissez-faire, bureaucratic and democratic leadership styles. The results of standard one way of variance, ANOVA, showed the following result in Table 13

The result in Tables 14 and 15 indicates that the calculated F value of 40.993 is higher than the critical F - value of 3.00 at .05 and of significance with 4 and 95 degrees of freedom. With this outcome, the objective that there is a noteworthy influence of leadership style on organizational performance was accepted. This infers that leadership style has an important influence on organizational performance.

\section{Discussion}

\section{Discussion of qualitative data}

Theme 1: It can be analyzed from theme in the analysis of data that the most noted leadership style that was collected from the population of study was transformational leadership style (40\%). Transformational leadership is a style that has had an enormous impact on leadership as a field of investigation [5]. Transformational leadership is the greatest studied leadership style through all disciplines. Transformational leaders remain charismatic; they motivate subordinates also they appeal to their ideals and moral values via creating and representing an inspirational vision of the future [6].

Theme 2: The results showed that $80 \%$ of the leaders where taskoriented. The view of the leader's behavior impacts the development of interpersonal normative contracts, group processes, besides to performance.

Theme 3: From the data analysis, it can be seen that there was a $40 \%$ no change, $40 \%$ negative change and a $20 \%$ positive change. In the analysis of the data being collected, it was concluded that worthy management leadership and motivation facilitated to develop teamwork in addition to the integration of individual, group and objectives.

Theme 4: From the data it can be seen that there was a $40 \%$ negative change, $40 \%$ positive change an $20 \%$ no change. As change agents, managers need to understand the significance of open channels of communication between top management and employees, organization as well Bernerth et al. [7].

\begin{tabular}{|c|c|c|c|c|c|c|c|}
\hline & & Autocratic & Democratic & Bureaucratic & Laissez-faire & Task-oriented & Total \\
\hline \multirow{5}{*}{$\begin{array}{l}\text { Leadership style } \\
\text { of manager } \\
\text { before }\end{array}$} & autocratic & 24 & 0 & 0 & 0 & 8 & 32 \\
\hline & democratic & 0 & 8 & 0 & 0 & 0 & 8 \\
\hline & bureaucratic & 0 & 0 & 8 & 0 & 4 & 12 \\
\hline & laissez-faire & 4 & 0 & 0 & 4 & 0 & 8 \\
\hline & Task-oriented & 0 & 0 & 4 & 0 & 36 & 40 \\
\hline \multicolumn{2}{|c|}{ Total } & 28 & 8 & 12 & 4 & 48 & 100 \\
\hline
\end{tabular}

Table 12: Cross tabulation of leadership style of manager before and after. 


\begin{tabular}{|c|c|c|c|}
\hline & & $\begin{array}{l}\text { Emphasis of } \\
\text { culture }\end{array}$ & $\begin{array}{l}\text { Manager influenced by } \\
\text { social behaviors }\end{array}$ \\
\hline \multirow{3}{*}{$\begin{array}{c}\text { Emphasis of } \\
\text { culture }\end{array}$} & Pearson Correlation & 1 & $.300^{* *}$ \\
\hline & Sig. (2-tailed) & & .002 \\
\hline & $\mathrm{N}$ & 100 & 100 \\
\hline \multirow{3}{*}{$\begin{array}{l}\text { Manager } \\
\text { influenced } \\
\text { by social } \\
\text { behaviours }\end{array}$} & Pearson Correlation & $.300^{* *}$ & 1 \\
\hline & Sig. (2-tailed) & .002 & \\
\hline & $N$ & 100 & 100 \\
\hline
\end{tabular}

Table 13: Correlation between the culture of the organization and manger's social behaviors.

\begin{tabular}{|c|c|c|c|}
\hline $\begin{array}{c}\text { Leadership style of } \\
\text { manager after recession }\end{array}$ & N & Mean & Std. Deviation \\
\hline autocratic & 32 & 1 & 1.76 \\
\hline democratic & 8 & 1 & 0 \\
\hline bureaucratic & 12 & 2.67 & 0.985 \\
\hline laissez-faire & 8 & 1.5 & 1.604 \\
\hline task oriented & 40 & 3.8 & 0.608 \\
\hline Total & 100 & 2.36 & 1.75 \\
\hline
\end{tabular}

Table 14: Summary data and one-way analysis of variances (ANOVA) of the influence of leadership style on organizational performance $(\mathrm{N}=100)$.

\begin{tabular}{|c|c|c|c|c|c|}
\hline Source of variation & $\begin{array}{c}\text { Sum of } \\
\text { squares }\end{array}$ & df & Mean square & F & Sig. \\
\hline \multirow{2}{*}{$\begin{array}{c}\text { Between Groups } \\
\text { Within Groups } \\
\text { Total }\end{array}$} & 163.973 & 4 & 40.993 & & \\
\cline { 2 - 6 } & 139.067 & 95 & 1.464 & 28.004 & .000 \\
\hline
\end{tabular}

Table 15: Summary data and one-way analysis of variances (ANOVA) of the influence of leadership style on organizational performance $(\mathrm{N}=100)$.

Theme 5: From theme 5 it was found that there was a $60 \%$ in the decrease in quality of service and a $40 \%$ no change. There are countless software systems, policies, procedures, prototypes etc., within the NCRHA. One main criticism remained that there were different systems in use in the NCRHA but that, while all worked well, there appeared to be no coordination or functional communication among them. This impacts the efficiency of all systems, especially financial ones.

Theme 6: From theme 6 what can be extrapolated that there was a longer waiting times by $40 \%$ of the population in the study. There remained a strong feeling that senior leaders in the NCRHA ought to have been held responsible for their actions, yet, this was not presently the case.

\section{Discussion of quantitative data}

The examination of the objective which specified: whether observed leadership styles have transformed as a consequence of the external environment manipulating the internal environment (NCRHA was proven to be a correct statement). From the analysis, it can be seen that employees perceived their leaders to be task-oriented and they were demotivated and their performance decreased after the recession decreased. There is an undesirable relationship between task-oriented leadership style and employee performance. The meaning of this is that that task-oriented leadership affected individual performance in a manner that compromised efficiency, individual innovation as well as creativity in NCRHA.

Discussion of Results on Research Objective 2: The research objective was to carry out an exploration of the leadership styles within the NCRHA. Organizational culture denotes to the beliefs as well as values that have occurred in an organization for a long time, in addition to the beliefs of the staff as well as the foreseen value of their work that influence their attitudes in addition to behavior. Managers typically modify their leadership behavior to achieve the mission of the group, and this might influence employees' job fulfillment.

Discussion of Results on Research Objective 3: The research objective of establishing whether recommendations might be made for enhancement with respect to the leadership processes inside the NCRHA it was revealed that this might be made to improve the performance of the NCRHA.

There remained a strong feeling that senior leaders in the NCRHA ought to be held responsible for their actions; though, this was not presently the case.

\section{Recommendations}

Anderson's [8] ideal visionary leadership's effect on customer satisfaction is being entirely mediated, though Powell [9] proposes that leadership directly affects firm performance. Both methods to demonstrating leadership, though, propose that businesses that have a greater level of quality performance will have greater levels of transformational leadership as opposed to companies that are ineffective quality performers [9]. Consequently, it is suggested that: Businesses with positive quality performance have considerably greater levels of transformational leadership than businesses with ineffective quality performance. Commencing the data analysis, it can be seen that the RHA quality had diminished because of the change in the leadership style from a transformational style towards a transactional style the literature supports this understanding.

\section{Relationship among the findings and research objectives}

The research results were mainly positively associated to the research aims and objectives. Styles had changed as a consequence of the economic downturn, and this body of work has emphasized the apprehensions of middle managers inside the system. There were equally strengths and weaknesses highlighted as a consequence of the qualitative in addition to the quantitative research.

\section{Appropriateness of selected methodology}

The precise research methodology was selected for this body of work. Through using the qualitative method of interviews, this led to a richness of data being delivered, which enhanced the original research objectives, and also directed the researcher in gathering rich and at times astonishing results. Maybe given more time, the investigator would have liked to replicate the interviews with their corresponding equals in a different geographical region for the purposes of a varied methodology to this body of work. By means of using quantitative data analysis in collaboration with the qualitative offered a more fruitfulness of data and a improved analysis of the study.

\section{Rationality of research}

It is thought that the research design and strategy were well coordinated, and completely addressed the original objectives. Furthermore, it was felt that the selected methodology plus the subsequent analysis of the data, created a precise reflection of the leadership styles under examination. Accordingly, the aims and objectives established in chapter 3 have been adequately answered to validate the rationality of the research. 


\section{Limits of research}

In retrospection, I would have been partial to interview more people, predominantly in relation to middle managers at front line level (Community services/acute/psychiatric/elderly/child and family). By means of carrying out this additional research, it can have an extra degree of fullness to the study, by giving feedback towards the middle managers who create these significant daily choices. In effect, it would have helped look at the problems from both sides. However, all interviewees were acutely aware of the challenges which their staff faced on a daily basis.

\section{Practical implications of upcoming research}

Through all systems, exist it attendance policies or financial regulations, there is a continual requisite to assess these systems and take a 360-degree analysis of them. This comprises the manager revising their particular position, and recognizing the strengths and weaknesses of to each system. Failure to recognize the findings will merely serve to weaken the organization's ability to move onward, further harmful to its reputation and stifling the chance to meet its potential as a world class health service.

Cheng [10] highlighted the necessity for all performance metrics to be assessed inside the public service. Systems are established to aid the public service, though, unless correctly managed, it will in effect be burdensome for staff to manage and will ultimately be either overlooked or implemented in a messy manner.

It is the purpose of this researcher to highlight the results of this thesis to the appropriate decision makers with the NCRHA at corporate level. It is wished that the conclusions and recommendations would be studied and acted upon, to contribution in making the NCRHA an enhanced place to work, whereas also aiding to conveying a better quality of service.

\section{Conclusion}

Per several changes taking place in the outside setting, administrations are being required to transform. The cultural burdens possibly make these worse, obliging managers to act out of personality or true principles. The leaders of nowadays are branded as "enforcers", coming out of non-profit-making years at the same time as trying to keep viability for their institutions and restructure their parts as inspiring leaders. Schein [11] understood that leaders had a great influence on the philosophy of their organizations and that their principles molded the foundation of the beliefs. This examination designates that if a detailed study were directed it might highpoint the negative culture that has developed.

The outcomes of this research established that leadership was affected by the outside setting and the changes enforced because of this. The principles of the organization were finally affected as the changes, although important, were sudden and essential but generated a different budding leader. It did not, however, provide an agreement as a full study was not finished. Overwhelmingly, the results approved with the original intention that leadership is influenced and affect by culture, particularly for the duration of economic downturns. The changes recognized were dissimilar to those seeming during normal cultural changes in that they affected the lowest line for both the organization as well as the staff members. The new culture ought to implement this with leaders initiating from the top and implementing the new revelation emergent after the financial crisis and global economic downturn.

\section{References}

1. Fox (2014) Advancing medical for population health management. In: Timothy $\mathrm{JL}$, Huerta R (ed.) Population Health Management in Health Care Organizations (p. 182). USA: Emerald Group Publishing

2. Bennis W (1985) Leadership: The Strategies for Taking Charge. New York Preston Hall, pp: 230-235.

3. Mintzberg H (1973) The nature of managerial work. New York: Harper \& Row, pp: 256.

4. Spreitzer G (1995) Psychological Empowerment in the workplace: Dimension validation and measurement. Academ Manage J 38: 1442-1465.

5. Antonakis Kark, Lowe, Gardner (2012) Transformational Leaders and Work Performance, The Mediating Roles of Identification and Self-efficacy.

6. Bass BM (1990) The implication of transformational and transactional leadership for individual, team and organizational development. Res Organizational Change Develop 231.

7. Bernerth (2011) Change fatigue: Development and initial validation of a new measure. Work Stress 25: 321-337.

8. Anderson RA (1994) The Effects of Transformational and Transactional Leadership on Quality Improvement Quality Manag J 16: 7-24

9. Powell B (1995) Managing Modern Healthcare: Knowledge, Networks and Practice.

10. Cheng (2011) Does health insurance coverage lead to better health and educational outcomes? Evidence from rural China? J Health Econ 31:1-14.

11. Schein E (1985) Organizational Culture and Leadership. Jossey-Bass Pub. 